\title{
The impact of policy effects on the Hungarian payments card market
}

\author{
László Kajdi ${ }^{1} \cdot$ Milán Kiss ${ }^{1}$
}

Accepted: 3 March 2021 / Published online: 25 March 2021

(c) The Author(s), under exclusive licence to Springer Nature Limited 2021

\begin{abstract}
As a major electronic alternative to cash, central banks and state administrations often support the development of card payments with regulatory and public policy steps. Hungary was extremely active in this field by executing POS-terminal installation programmes or setting limits to interchange fees a year before the European regulation. Within this study we investigate, how these measures contributed to the recent evolution of Hungary's payment card market. Using the comprehensive dataset of the Central Bank of Hungary, we provide empirical evidence using time-series analysis methods, that both policy steps had a significant positive effect on the domestic card payments scene.
\end{abstract}

Keywords Interchange fee $\cdot$ Card payments $\cdot$ Payments policy $\cdot$ Regulation $\cdot$ Time-series analysis $\cdot$ Empirical evidence

\section{Introduction}

Finding the most effective way to incentivize the usage of electronic payments is a foremost priority for several actors of the economy. Central banks, governments and state administrations, card companies, payment service providers (PSPs) and quite often merchants and consumers are all motivated to facilitate this process. In most countries cash is still the most popular payment method nowadays, as the European Central Bank's comprehensive study (EsselinkHernandez 2017) clearly shows for instance [1]. Nevertheless, the more frequent usage of electronic payment methods can bring higher level of transparency, lower tax evasion and social costs attached to retail payments (Schmiedel et al. 2012; Danish Payment Council 2018) [2, 3] as several studies describe. For market stakeholders - unlike cash transactions - these payment methods mean new business cases and revenue streams, as well as the more in-depth knowledge of customers. However, it should be emphasised that the issue of financial inclusion should be a foremost priority to policy makers as well, which in practice means that the increased usage of electronic payment methods cannot prohibit those

Milán Kiss

kissm@mnb.hu

1 Magyar Nemzeti Bank, Directorate Financial Infrastructures (Central Bank of Hungary), P.O.B. 1850, Budapest 1054, Hungary from using cash who do not intend or cannot (for instance due to high fees) use electronic solutions.

Until the recent global spread of instant payment solutions, card payments were the major alternative - and in several countries still are - to cash. Cards provide convenient, and nowadays, especially with the widespread prevalence of contactless technology, fast user experience in point-of-sale and online payment situations. Another major advantage is that the cards of main international schemes can be used globally, under the same processing, refunding and chargeback rules. Therefore, it has been in the centre of attention how the turnover of this payment method could be increased. However, different actors have different perspectives: while for card companies all transactions bring additional income, for PSPs and technical service providers the question is perhaps more sophisticated, since they have to find their optimal level of participation on the issuer, or the acquirer side, or both (i.e. due to the economy of scale nature of the market, high interchange fees and low transaction numbers might force certain players to leave the market). For merchants providing the option of convenient card payments might generate additional turnover, but also brings extra acquiring costs. Some studies (Vickers 2005, Rochet-Tirole 2008) highlighted, that merchants might face the problem of 'must-take' cards, i.e. they cannot refuse such payments even if their operating costs increase significantly [4. 5]. And beyond these aspects, central banks and governments intend to reach the thin balance between a flourishing payment market with solid operational profits and the widest 
possible use of these solutions by customers. In other words, market concentration might reduce costs in the short-term due to the economy-of-scale nature of processing transactions, but in the long run it might hinder market competition.

In Hungary several public policy steps - POS-terminal installation programmes, interchange fee regulation - were taken, and the prevalence of contactless technology - similarly to other countries in the region (Rolfe 2016) - is rather high even in international comparison [5-7]. This is presumably due to the fact, that the market in these countries was - and to some extent still it is - less developed (i.e. lower card possession rate and usage), therefore it was easier to switch to the new contactless technology. Thus, the in-depth analysis of these individual effects can bring important conclusions to other countries as well, which intend to develop their payment card market. Our major research question is how the different factors influenced the steep increase in the card payments turnover in Hungary during the recent years, and which policy steps can be identified as "best practice" for other countries as well. We also intend to contribute to the discussion concerning the evaluation of the effects of European Interchange Fee Regulation (IFR). ${ }^{1}$

After the introduction of the regulatory background, in Chapter 3 we provide an overview of the relevant international literature, while in the next part we describe our datasets and applied methods. Within Chapter 5 we present our descriptive results as well as the time-series analysis based on Hungarian data, after which we draw our conclusions focusing on public policy and regulation effects.

\section{Regulatory background and case law}

In our paper we examined two major policy related regulatory steps taken by EU and Hungarian government: IFR and POS installation programs. Since the POS implementation programs were rather a fiscal decision of Hungarian governmental institutions no case law exists, therefore the policy (regulation) details would be described in the descriptive statistics section (Chapter 5.1.)

On the other side there had been several competition authority and court cases - both on EU and Hungarian level - which finally led a European Economic Area (EEA) wise - interchange fee regulation. Since we are trying to identify the effects of policy measures in an empirical work, we would like only to highlight cases, but do not go into their very details.

\footnotetext{
${ }^{1}$ Regulation (EU) 2015/751 of the European Parliament and of the Council of 29 April 2015 on interchange fees for card-based payment transactions.
}

The European Commission (EC) and the Hungarian Competition Authority (GVH) had competition related cases against the main two international card companies: MasterCard and Visa. The outcome of these cases finally resulted the proposal of IFR which has EEA relevance.

EC had four cases on interchange fees: Comp/34,579-MasterCard I, Comp/40,049-MasterCard IIthe inter-regional interchange fees leg, Comp/29,373-Visa International, Comp/39,398-Visa MIF. Within these cases EC investigated how Visa, MasterCard and their partner payment service providers determined their interchange fees in four party payment card schemes within member states of EU and intra-region. To perceive the competition law relevance of the interchange fees, one first needs to understand the interchange fee itself and its purpose. In the four-party payment card schemes there are four (plus one) members: the payee who accept cards (usually a commercial unit, a merchant), the payee's payment service provider who provides payment instrument acquiring services as per Directive No (EU) 2015/2366 (PSD2), the payer who holds the card and the payer's payment service provider that issues the payment card to the payer as per PSD2. Furthermore, the additional member of the scheme is the card company that operates the scheme, sets the scheme rules and provides clearing services to the payment service providers. The payee pays a fee to its acquirer payment service provider that can be broken into two categories: merchant fee that the payee pays for the acquiring service and interchange fee that is paid to the issuer payment service provider to encourage more cards to issue, and to maintain cardholders' fees on a lower level and to cover at least part of card production and other development costs on the issuer side. Therefore, the card market is considered two sided as the issuer and acquirer siders are interdependent. The more customer wants to pay with a given card brand, the more merchant is willing to accept it, but the more merchant is willing to accept a given brand, the more customer wants that specific brand's card. Hence, it is crucial on this market the actual value of the interchange fee as it balances out the issuer and acquirer side of the market.

The above-mentioned cases focus on the antitrust aspect of how the interchange fee was determined: as a result of a decision of the card company and the payment service providers; and the competition limitation effect of the interchange fee: the higher fee encourages to issue more cards of a given brand that have negative effect of the consumers through a pass-through effect (meaning that the higher acquiring costs could lead higher product and service prices), and since a given card brand's practice of determining of the interchange fee may differ from country to country or region to region there could be cases where one card brand could set high interchange fees which limits the competition on the market. 
The GVH also investigated the possible competition law breaches in the Hungarian card payments market in relation to interchange fees in the cases: $\mathrm{Vj} / 18 / 2007$. against Visa and banks, Vj/46/2012 against MasterCard, $\mathrm{Vj} / 78 / 2013$. The scope of the GVH investigations were the same as in case of the EC. Since this work focuses on the policy effects - among others - IFR that can be considered as a result of these competition law cases, we only briefly refer to the fact that these EC and GVH cases were challenged at the Court of Justice of European Union.

As it was shown by GVH in the case $\mathrm{Vj} / 46 / 2012$, after the EC case Comp/39,398- Visa MIF a cap was introduced on the Hungarian interchange fees as well, which resulted a significant drop in Visa's market share. Therefore, the Act LXXXV of 2009. on the Pursuit of the Business of Payment Services (PSA) was amended ${ }^{2}$ and from January 2014 introduced a 20 basis points cap on the interchange fees in case of debit cards and 30 basis points on credit cards. The MasterCard filed to the Constitutional Court of Hungary (AB) to challenge the measures that introduced the cap, however MasterCard's request to abolish the interchange fee rules was rejected in decision 3248/2014. (X. 14.). The Hungarian regulation later was replaced by EEA wide IFR which is described in detail below in Sect. 5.1.

\section{Literature overview}

From the possible policy steps to support the development of payment card market, the relevant literature focuses mainly on the regulation of interchange fees, and especially three main topics. First, there was a debate if policy measures to limit interchange fees (eg. a regulation to determine a cap) should be introduced at all. The second argument was on the issue whether the optimum level of interchange fee could be determined, and what would be the best method to calculate that level. Third, there was extensive discussion on the measurement of the effect of the policy steps taken, for instance on introduction of the regulation of interchange fees in the European Union. In this current overview the above described three main topics would be covered, furthermore a study issued on the Hungarian payment card market and interchange fee regulation is briefly presented.

\section{Introduction of interchange fees}

Börestam and Schmiedel (2011) focused in their study to understand whether interchange fees should be regulated or not [8]. According to the competition authorities' decisions in the late $2000 \mathrm{~s}$, multilateral interchange fees for cards

\footnotetext{
$\overline{2}$ See Article $35 / A$. of PSA.
}

were considered to be decisions of associations of undertakings, or as agreements between undertakings, which restrict competition. Although, it was not questioned by competition authorities that such agreements could bring benefits to customers, which might make them compatible with competition law, but in the majority of the cases financial institutions could not prove these benefits. Europe Economics (2013) investigated the possible effects of the introduction of interchange fee regulation in the UK [9]. The study claims that such regulatory steps may lead losses in issuers' revenues of up to GBP 2.5 billion annually, and issuers could aim to recoup such revenue loss by raising cardholder fees. In addition, there could be additional side effects, such as complexities for the recovery in UK bank lending, SME financing, quantitative easing, universal credit, innovation, and fraud control. Reisinger and Zenger (2014) analysed the necessity of interchange fee regulation within a theoretical model [10]. They showed that it is critical to prohibit surcharging to prevent pass-through effects, which means that merchants would not be able to set a fee for card acceptance alone. In the presence of no surcharging, incentives to invest in retailer services are bigger than compared to cases where surcharging is allowed. In Hungary, Keszy-Harmath et al. (2012) in a joint publication of the Central Bank of Hungary (MNB) and the GVH before the actual regulatory steps were taken studied the Hungarian card payment market [11]. After the profound analysis of the Hungarian payments card market, the main conclusion of the study was that the regulation of interchange fees could positively contribute to the development of the domestic card payment scene.

\section{The optimal level of interchange fees}

Perhaps the most widely used method to determine the optimal level of interchange fees is by performing the so-called Merchant Indifference Test (MIT) or in other name the Tourist Test, which aims at determining a level of interchange fee that makes the merchants indifferent between a transaction by cash or by card. In its study the European Commission (EC) (2015a) [12] came to the conclusion -similarly to Górka (2014) [13] concerning the Polish market - that the marginal cost of cash compared with the cost of the same transaction executed with a card without the interchange fee is higher, therefore the costs of cash exceed the cost of card per transaction. The EC also claims that the merchants in the sample of the study would be better off to execute a payment with cash rather than with card. This means that the interchange fees were on average above the indifference threshold for the merchants in the sample, i.e. they were considered to be high. Bolt et al. (2013) [14] also investigated the issue through the application of MIT on Dutch cost data from 2002 to 2009 . While they mainly focused on the justification of the methodology determining the interchange fee, 
the relevant claim of their study is that in a market where the social costs of debit card payments are lower than those of cash (as in the case of the Netherlands), using Tourist Test to define interchange fees would not necessarily mean that potential social cost savings are realised. Furthermore, other aspects of the market along with other effects than interchange fee may be even more relevant on card acceptance, hence the Tourist Test may not be the best method to find the optimum interchange fee level.

\section{Effects of interchange fee regulation}

From the previous interchange fee regulations, one of the most extensively researched is the one in the USA. LayneFarrar (2013) [15] aimed to determine whether the interchange fee reduction cap imposed under the Durbin Amendment (as part of the Dodd-Frank Act) was efficient in the US market. The paper concluded that the interchange fee cap seemed low in a given segment of merchants, while in another segment it can be considered too high, therefore it had different effects in different merchant categories. Wang (2012) also suggested, that certain merchants, specialising in 'small-ticket' transactions experienced adverse effects, and instead of capping maximum fees, setting the weighted averages of interchange fees would be more favourable from a theoretical point of view [16]. Shy (2012) was also trying to capture the effect of the interchange fee reduction in the USA on different merchants [17]. The study intends to identify the transaction values for which merchants pay higher and lower interchange fees under the new rules. The results showed that changes in fee structures have effects similar to changes in tax schedules; they both increase the burden on some agents and reduce the burden on others. Hayashi (2012) [18] found that the regulation had diverse effect on card issuing banks as most of the card networks set different interchange fee levels for them. The policy measure increased the competition as evidenced by one of the main card network's market share decline. Regulated banks' interchange fee revenues decreased (with a possible increase of consumer fees), while the exempted banks' turnover remained the same. The intervention appeared to have the expected effects in general, such as raising the level of competition among card networks and shrinking the fees charged to merchants. In his second article, Hayashi (2013) [19] focuses on how the regulations and the industry's reactions to them affected merchants, consumers and the overall efficiency of the payments system. According to the result the effects varied for different groups: many merchants experienced declines in their debit card interchange fee expenses, while others experienced an increase in the fees they pay per transaction. Concerning consumers, no significant increase in the cardholder fees could be identified. One of the main goals of the US regulation was to increase the consumer welfare, however by the time of the study it was too early to tell if the US payment market had become more efficient. Zywicki et al. (2014) showed in their study, that certain PSPs applied cross-pricing after the capping of interchange fees, and instead of increasing card fees they raised the level of account fees (decreasing the availability of fee-free accounts) [20]. This study did not find any evidence for pass-through from merchants to customers, hence in their conclusion the regulation resulted a transfer from households to large retailers. A similar conclusion was reached by Evans et al. (2013), suggesting that banking fees grew even more after the regulation than merchant acquiring fees dropped [21].

Iranzo et al. (2012) investigated an interchange fee reduction in Spain happened in a five-years period from 2006 to 2010 [22]. To reduce interchange fee, a government-enforced Agreement was signed by main Spanish merchant associations and card schemes. According to the study, there was a 58.7 percent reduction in interchange fees on average, which amounted to EUR 3.329 bn in absolute numbers over the five-year period. This measure lead to a 51.3 percent average decrease (EUR 2.749 bn in five years) in Merchant Service Fees (MSF), which are paid by merchants for card acceptance, while consumer costs (annual card fees) increased by 50 percent, which meant EUR 2.350 bn over the five year period. The authors claim that the reduction of interchange had clearly harmed consumers by raising cardholder fees and reducing card benefits (such as insurance attached to the cards), and they found no evidence that consumers had benefitted from lower prices following the decrease of interchange fees. Furthermore, the capping of interchange fees adversely affected competition and incentives to innovate, thus slowed down cash displacement.

Within his extensive analysis on interchange fees, Górka (2018) [23] shows the latest results of the economics of two-sided markets including business models, indirect network effects and regulatory concerns on market failures, that might appear. After a comprehensive description of public authorities' measures in France, Mexico, Canada, Israel, India and China, case studies are presented from Australia, USA, Spain with an overall positive assessment of the interchange fee reform in these countries. An empirical investigation is also performed on Polish data to evaluate the effects of Polish interchange fee regulation, which happened in four stages: in 2012, 1st January 2013, 1st July 2014, and 29th January 2015. Two researches were presented: first, evidence on the pass-through effect from two subsequent merchant surveys are described. The results show that the level of MSF was halved, the competition within the acquiring market increased, but acquirers were able to maintain relatively higher margins on approximately 60 percent of merchants (mainly small and medium-sized) which did not renegotiate or sign a new contract. The second research aims to 
investigate the supposed impact of the interchange fee reductions on the growth of the card acceptance network and card usage in Poland by using time-series analysis econometric methods. The impact of interchange fee reductions on card payments acceptance and card usage in the years 2013-2016 was measured by comparing two scenarios: the first one, in which it is assumed that the interchange fee remains constant over the entire period at the level from the year 2012 (1.6 percent); the second one, in which the interchange fee is gradually reduced. The models showed that the change in interchange fees had a meaningful positive influence on the card payments acceptance network and the card usage in Poland. The relationship is inversely proportional, which means that the fall in interchange fees caused the rise in the number of acquiring merchants and card transactions.

Ardizzi and Zangrandi (2018) found evidence that the 2015 EU IFR measures led to a sizeable drop in merchant fees and to an increase in the acceptance of card payments (measured as transactions per terminal) by using by using a panel of Italian banks [24]. In the research it was found that between 2015 and 2017, interchange fees dropped by 37 percent while MSFs (which include the acquirer's margin) decreased by 22 percent, and interchange fees appears to account for 30 to 40 percent of the decline in MSF. The authors also proved that the regulation led to an increase in merchant acceptance (the number of card transactions per POS terminal) of approximately 8 to 11 percent and explained 30 to 40 percent of the increase in merchant acceptance observed between 2015 and 2017.

In his work Veljan (2018) argues that policy measures should not rely solely on complex theoretical models, but empirical data also should be considered during the decision making [25]. According to the paper, as a consequence of the European interchange regulation, card-issuing banks across Europe registered approximately EUR 4.2 bn revenue loss, with Germany and the UK suffering the greatest impact. He also claimed that 80 percent increase in processed card volumes would be necessary to compensate for the losses, while the European card payment market grew at an average of 9 percent following interchange fee reductions, furthermore the total card payments increased in value by 12.5 percent from 2015 to 2016 . The research showed that the results of the partial rank correlations empirically confirm that a very low statistical relationship could be observed between the interchange fee and card issuance, usage and acceptance, while no statistical relationship can be observed for the other variables.

The EC also executed extensive research concerning the effects of IFR (EC 2020) [26]. The study covered all 28 EU Member States, and surveyed merchants, PSPs, consumer associations and card schemes as well. As the main conclusion, the results showed that due to the IFR, MSFs decreased, which lead to a wider card-acquiring network.
It is also important, that no evidence was found for the increase of cardholder fees as a response of issuing PSPs for their declining revenues. Nevertheless, the study suggests to maintain the exemption of commercial cards from the maximum limits defined by IFR.

\section{Data and methods}

For our analysis, we used the datasets of the MNB, collected from PSPs. The main advantage of these datasets is that they are comprehensive and required by regulation (it is mandatory to submit these data to MNB), thus the usually significant bias of merchant surveys can be avoided. Previous sample surveys among merchants - e.g. the one carried out by the GVH - showed that the financial awareness of merchants can be considered rather low in general $(\mathrm{GVH}$ 2019) [27] The fee burdens reported by merchants in the survey were much lower than those which are collected by the MNB from PSPs. Therefore, we believe that our analysis can improve significantly the general knowledge regarding the effects of policy steps in this field.

The MNB has data covering the infrastructure (number of cards, POS-terminals etc.), the turnover (number and value of card not present and POS, domestic and cross-border transactions) and the revenues of PSPs from the provision of card acceptance service. Some of these data are also available by merchant categories (defined by quarterly card purchase turnover). The frequency of the data collection on payment card infrastructure and turnover was semi-annual from 2010 to 2013, which was changed to quarterly reports from 2014. Data on PSP revenues from card acquiring services are available quarterly, but only from 2013, and the total merchant service fees (MSF) are broken down to three categories: interchange fees, fees related to POS terminals and other fees. As a consequence of these, those data, which were not available on a quarterly basis for certain periods were back-casted. The MNB also collects data from PSPs on the cardholder fees (card issuance fees and annual fees), and from this - together with the number of cards with different fee conditions - a weighted average can be calculated for each year.

Besides the aforementioned advantages of the available data, there are some drawbacks as well. During the last couple of years, the volume of card-payment turnover processed by cross-border PSPs increased quite remarkably. This can be followed by calculating the difference of the turnover data between the issuer and the acquirer side, i.e. the turnover reported by issuer PSPs is gradually becoming larger than the data from acquirer processors (see Fig. 1). The reason for this is that so far these cross-border PSPs have not reported to MNB, therefore a part of the market is not covered by our data. This might cause some bias, since - according to market 
information - cross-border acquirers rather focus specifically on smaller merchants. The emergence of these PSPs - which happened after the IFR - reduce market concentration and the market share of those PSPs, which participate in the Hungarian market both on the issuer and acquirer side. According to Veljan (2020), market concentration can have a significant effect on interchange fees [28]. Since there are no comprehensive data available on the cross-border acquirers (no data on the number of merchants, turnover (Figs. 2, 3, 4) by merchant categories, ratio of POS terminals with contactless function etc.) we decided not to analyse the effects of market concentration in the time-series models, but only present descriptive data (estimates, see Fig. 5). However, due to the currently relatively small market share of these PSPs we believe that our analysis provides valid results. Also, because of these PSPs target mainly small merchants and appeared after the IFR, it is valid to presume that the inclusion of them would just strengthen the findings of our models.

Unlike EC (2015a) there were no cross sectional or panel, but only time series data available to identify the partial effects of our policy variables, thus we needed to find an appropriate time series model [12]. Based on our dataset it could not be assumed that the dependent and independent variables have a mutual effect to each other, therefore vector autoregression (VAR) models did not seem adequate. Hence our attention turned to the workhorse of time series modelling: autoregressive integrated moving average (ARIMA) models similarly to Górka (2018), who also used ARIMAX approach in his empirical work [23]. Within ARIMA models the current values both depend on the values of the previous periods (i.e. variable of interest is regressed on its own lagged values) and the error terms, and data are replaced with the difference between the current and previous values in order to reach stationarity. To determine the ceteris paribus effect of our policy variables we needed to include exogenous input variables, thus ARIMAX model was chosen (as in the data we could not identify seasonality, we dropped S-ARIMAX models).

\section{Results}

\section{Descriptive results}

In spite of the dynamic improvement during the last couple of years, currently the Hungarian retail payments market is rather cash dominated (Illyés-Varga 2015; MNB 2020b), [29, 30] similar to most of the countries. However, the popularity of payment cards among Hungarian consumers rose steeply during the last couple of years by an average of 20-25 per cent year-on-year. Currently this payment method is the second most frequently used after cash, and the annual number of transactions exceeded 900 million in 2019.

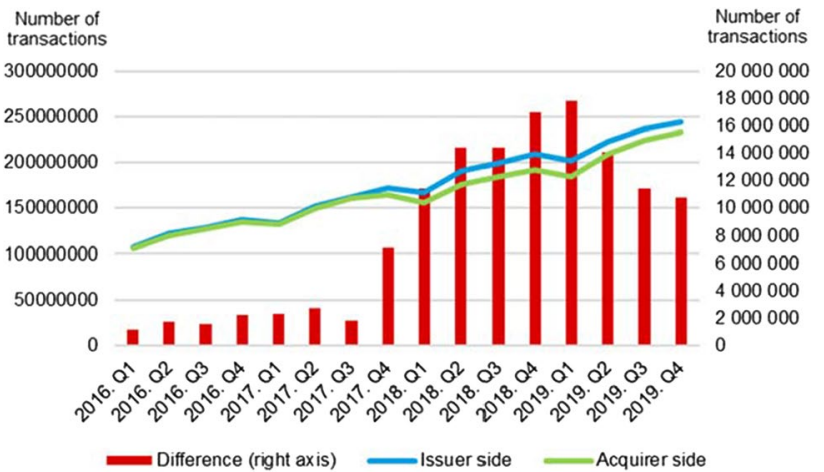

Fig. 1 Number of domestic card payment transactions with cards issued in Hungary, reported by PSPs from the issuer and the acquirer side Source: Authors' calculations based on MNB data

The favourable processes on the card payments market and the dynamic increase in the turnover can be traced back to several factors, some of them came from the Government and the MNB. One way to incentivize the usage of payment cards is to support the widening of acceptance network. In Hungary, MNB carried out a county-level pilot programme for POS-implementation with the cooperation of the two major card companies in 2013. On the basis of the experiences from this pilot project, the Ministry of Finance started a national one-year programme from December 2016, which was later lengthened. The two programmes altogether aimed to implement a total of 60,000 POS-terminals. PSPs could apply for state financial support with the following conditions ${ }^{3}$ :

- they implement the terminals to merchants where previously no card acquiring was available;

- state funding is HUF 80,000 (appr. EUR 250) per terminal;

- the POS must be in operation for at least 2 years;

- the device must enable contactless payments;

- MSF must have an upper threshold of 1 per cent of the total card payment turnover.

With the contribution of these programmes, the Hungarian card acceptance network started to grow during the last couple of years. The number of physical merchant outlets rose from less than 70 thousand at the end of 2012 to almost 114 thousand in 2019 (MNB 2020a) [31]. The ratio of the contactless POS devices also expanded, reaching almost 90 per cent at the end of 2019. The plateau after the second half of 2017 can partly be attributed to the increasing presence of cross-border card acquirers, which are currently not part of MNB's datasets.

\footnotetext{
${ }^{3}$ See the Decree of the Ministry of National Economy No. 47/2016. (XII. 6.) on support to increase the number of bank-card terminals.
} 


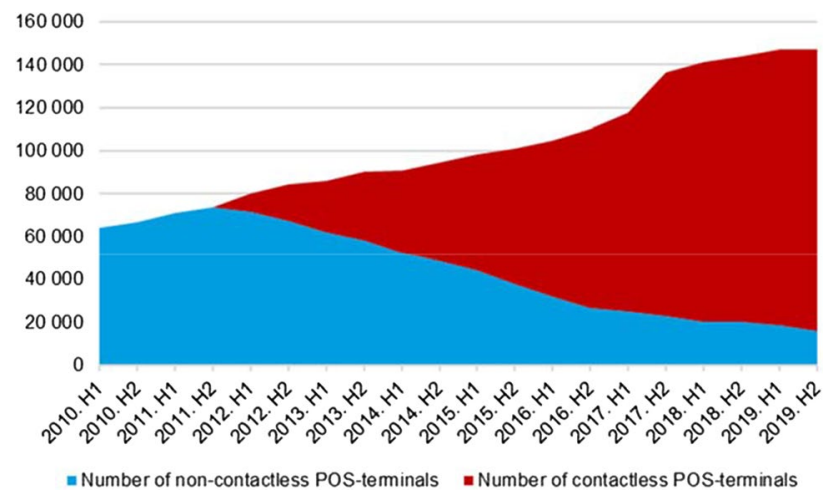

Fig. 2 Number of POS-terminals in Hungary Source: Authors' calculations based on MNB data

Besides POS-implementation programmes, another important intervention area is the regulation of interchange fees. As also described in Chapter 2 and 3, interchange fees were affected by numerous competition authority investigations in several countries ${ }^{4}$ including Hungary, and the European Commission (EC) also dealt with this topic in several rounds. In 2002 the EC adopted a competition law decision to reduce Visa Europe interchange fees applied on crossborder transactions within the EEA ${ }^{5}$. Five years later the EC also decided that MasterCard's cross-border interchange fees within EEA countries restrict competition under EC Treaty rules on restrictive business practices (Article 81(1) ${ }^{6}$. Although it was challenged by MasterCard, the measures were upheld after the decisions EU General Court and the EU Court of Justice. Parallel with these processes, the MNB and the Hungarian state administration, especially the regulator Ministry of Finance were also extremely active in this field in Hungary. A domestic regulation ${ }^{7}$ stepped into effect one year before the new European IFR, using the upper thresholds for interchange fees in the case of debit and credit cards $(0.2$ and 0.3 percent of the transaction value respectively) which were applied in the IFR later. As Fig. 3 clearly shows, after the Hungarian IFR, not only interchange fees, but the total MSFs started to drop in almost all merchant categories, thus card acceptance became cheaper for merchants. Nevertheless, it is also to admit, that in the case of smallest merchants, fees are still significantly higher, although there was gradual improvement.

\footnotetext{
${ }^{4}$ See UK Supreme Court decision for instance: https://www.supre mecourt.uk/cases/docs/uksc-2018-0154-judgment.pdf

5 https://eur-lex.europa.eu/legal-content/EN/TXT/?uri=CELEX\% 3A32002D0914

6 See for example: https://ec.europa.eu/commission/presscorner/ detail/en/IP_07_1959

${ }^{7}$ See PSA.
}

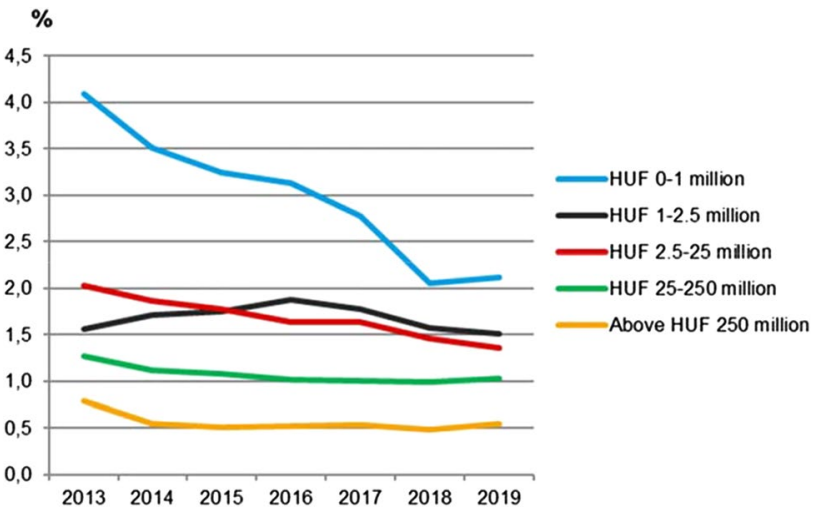

Fig. 3 Merchant service fees in Hungary as a ratio of card payment turnover in different merchant categories Source: Authors' calculations based on MNB data. *Categories were created on the basis of quarterly card payment turnover of the merchants

The IFR also intended to further increase the financial awareness of merchants (EC 2015b) [32]. A part of this regulatory aim was the so-called 'Unblending' requirement (Article 9) which comprised of two points:

1. PSPs must set individually specified fees for different categories and different brands of payment cards with different interchange fee levels;

2. acquirers shall include in their agreements with payees individually specified information on the amount of the merchant service charges, interchange fees and scheme fees applicable with respect to each category and brand of payment cards, unless merchants request otherwise in writing.

This supports merchants to be fully aware of the fees charged by their PSPs, help them to compare their current fees with business proposals of other PSPs, thus in the long run facilitate market competition. As Hungarian data show, this type of financial awareness gradually grew after the stepping into effect of IFR, which could contribute to the decreasing merchant fees presented above. However, it

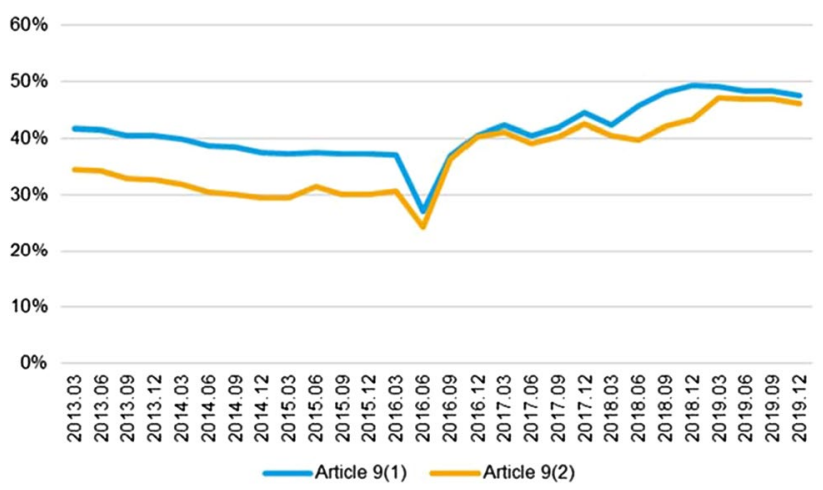

Fig. 4 Ratio of merchants in Hungary requesting unblended information Source: Authors' calculations based on MNB data 
should be noted, that in spite of the moderate improvement in this field, half of the merchants still not receive detailed information on the different fees. In addition to that, based on these data we cannot see to what extent merchants use the received detailed information, i.e. whether they actively seek for cheaper options.

The decrease in the level of interchange fees can also help to reduce market concentration and facilitate the market entry of new service providers. With high interchange fees, those PSPs which have a large share of on-us transactions (i.e. they are significant players both on the issuer and acquirer side) have comparative advantage to others. It is because they do not have to pay interchange fees for on-us transactions, when the cardholder and the card acquirer merchant is the client of the same PSP, thus these PSPs can provide card acquiring services cheaper, compared to those PSPs, which only acquire transactions. Reducing interchange fees can diminish this comparative disadvantage of card acquirer PSPs, and facilitate their market-entry. Figure 5. gives a brief overview on the Hungarian situation, showing constantly growing market share of those PSPs, which only acquire transactions.

The third major influencing factor of the Hungarian card market was the spread of contactless technology. Making the user experience much more convenient and the whole payment process faster, contactless payments became extremely popular, and currently more than 90 per cent of card payments at physical points of sale are carried out in this manner. Besides the modernisation of acquiring devices (i.e. currently mainly POS-terminals see Fig. 2), the ratio of contactless cards also grew rapidly. Meanwhile the total number of payment cards slightly increased, which can refer to the fact that according to our descriptive data, the IFR did not

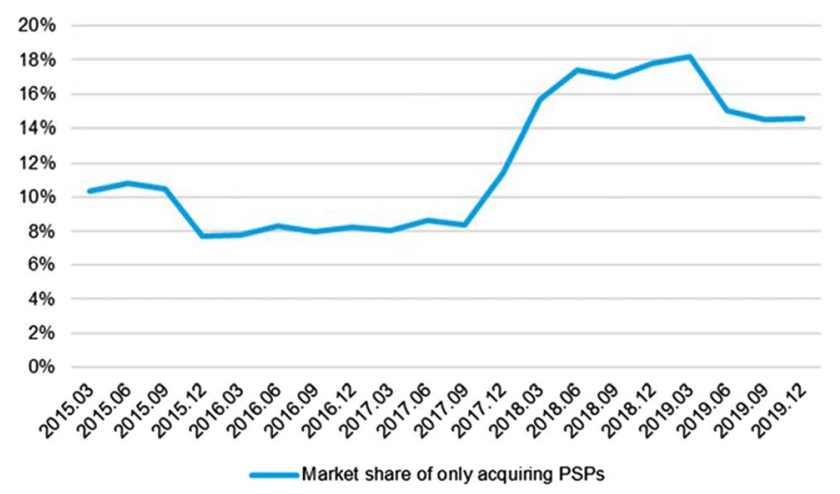

Fig. 5 Share of those PSPs in Hungary which only acquire transactions (number of transactions) Note Before 2015 less than two PSPs data were available, therefore we cannot publish data due to dataprotection reasons. The turnover of cross-border acquirers was also included, since according to market information, the vast majority of these PSPs do not issue cards. The turnover of cross-border acquirers was estimated as the difference between the issuer and acquirer side (see Fig. 1) Source: Authors' calculations based on MNB data.

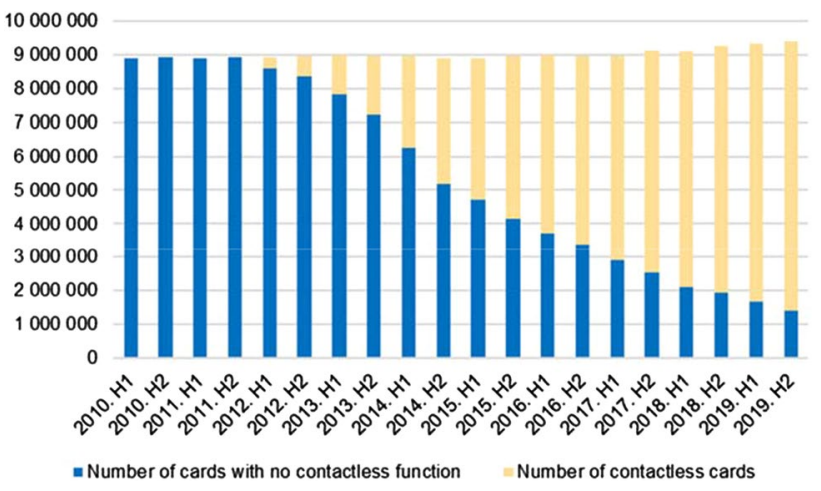

Fig. 6 Number of payment cards issued in Hungary Source: Authors' calculations based on MNB data

have a greatly unfavourable effect on the issuer side. One of the main arguments of card companies and sometimes PSPs against IFR, is that it causes adverse effects on the issuer side: the revenues of issuer PSPs will decrease with lower interchange fees, which result in higher cardholder fees, causing the decrease of the number of payment cards. As we can see on Fig. 6, in Hungary this was not the case. One explanation for this, is that payment cards are nowadays essential instruments for modern life. Most of the retail consumers use them, at least to withdraw their income at the nearest ATM. Thus, some might say, that consumers are not in a position to cease their payment cards, and card issuing PSPs can easily raise the cardholder fees, in order to compensate the reduction of interchange fee revenue streams. Nevertheless, the MNB also has comprehensive data on payment card conditions (i.e. issuing fees, annual fees etc.), and no major increase could be identified during the last couple of years.

It is also to be mentioned that, as for instance studies (Evans et al. 2013, Zywicki et al. 2014) from the U.S. market show, PSPs on the issuer side can also apply cross-pricing, and instead of cardholder fees they increase other items like account management fees [20, 21]. However, we did not analyse this (only the effects on card holders' fees) in our time-series models for two reasons: on one hand, as the data of the MNB (2019) shows, no major changes occurred since 2014 in the fees of different payment services; on the other hand, around 2014 other regulatory requirements (free cash withdrawal under a monthly limit of HUF 150,000; special tax on credit transfers) caused major changes in other fees, hence we do not see it feasible to build models where specifically the effect of IFR to the fees of other payment services could be identified.[33].

\section{Time-series analysis}

As described in Chapter 4. we used ARIMAX time-series models to quantify the effects of different regulatory and public policy measures on the development of the 
Hungarian payment cards market. When setting the models, we focused mainly on the IFR, nevertheless we also included other major factors, like the POS-implementation programme or the spread of contactless (NFC) technology. We examined the period from 2013, since detailed MSF information was available only from that point. Since we had data with quarterly frequency, this meant altogether 28 periods in our models between 2013 and 2019.

\section{IFR effects on the acquirer side}

First, we tried to identify the effects of IFR on the acquirer side, i.e. did the reduction of interchange fees contributed to the growing card acceptance network in Hungary. As we introduced on Fig. 3., according to our descriptive data the IFR caused decrease in MSFs, therefore we would expect that parallel with the shrinking costs, more and more merchants choose to provide card acquiring for customers.

In order to ensure stationarity, we used the first logdifferences of our variables, which was followed by Augmented Dickey-Fuller tests. In the first model, our dependent variable was the number of card acquiring merchants (dl_merchnum), and we tried to capture the relationship with the following explanatory variables:

- household consumption (dl_consum) (HUF million), which refers to the general economic situation in the country

- spread of contactless technology:

o ratio of contactless POS terminals among all devices (dl_posnfe)

o ratio of contactless cards among all cards (dl_cardnfc)

- ratio of terminals implemented in the framework of the national POS-implementation programme (dl_posrat)

- merchant costs and interchange fees:

o interchange fees (dl_mif): we used the historical data on interchange fees

o ratio of MSF to card payment turnover (dl_incrat) to capture the volatility in merchants' costs

o ratio of interchange fees to card payment turnover (dl_mifrat) to capture not only the absolute level of interchange fees (dl_mif), but also their relative burden on merchants

- card payment turnover (dl_cardtr): number of card transactions

In line with these, our equation was the following: number of card acquiring merchants (dl_merchnum $)=\beta_{0}+\beta_{1} \mathrm{dl} \_$consum $+\beta_{2} \mathrm{dl} \_$posnfc $+\beta_{3} \mathrm{dl} \_$card -
Table 1 Results of ARIMAX model on the number of card-acquiring merchants in Hungary Source Authors' calculations based on MNB data

\begin{tabular}{ll}
\hline Variable & Coefficients \\
\hline Household consumption (dl_consum) & $\mathbf{0 . 1 4 1 *}$ \\
& $(2.277)$ \\
Ratio of POS-terminals installed within the State's & $\mathbf{0 . 0 6 2 *}$ \\
programme (dl_posrat) & $(2.330)$ \\
AR(1) & $\mathbf{0 . 4 7 9 *}$ \\
& $(2.567)$ \\
Constant & $\mathbf{0 . 0 0 9 *}$ \\
& $(2.171)$ \\
\hline
\end{tabular}

*Indicates significance at 5 percent level respectively

Numbers in parenthesis are t-statistics.

$\mathrm{nfc}+\beta_{4} \mathrm{dl} \mathrm{l}_{-}$posrat $+\beta_{5} \mathrm{dl} \_\mathrm{mif}+\beta_{6} \mathrm{dl}$ Incrat $_{+} \beta_{7} \mathrm{dl} \mathrm{l}_{-}$ mifrat $+\beta_{8} \mathrm{dl} \_$cardtr $+\mu$.

Our results showed that the development of the number of card acquiring merchants was mainly driven by household consumption in Hungary, while the national POSterminal implementation programme also had significant (but moderate) positive effects. The significance of AR(1) indicates, that there is a quarterly delay in the effects of the POS-programme and the consumption, i.e. the number of card acquiring merchants will increase in (Table 1) the subsequent period. We can also see that we found no empirical evidence for a direct relationship between IFR and the development of the Hungarian card acceptance network.

We also ran regressions with the same explanatory variables described above, but with the ratio of MSF to card payment turnover as a dependent variable. Our purpose was to examine the factors, which help to reduce MSFs. According to a previous merchant survey, conducted by the GVH (GVH 2019), [27] the majority of those merchants which do not accept cards, indicated cost as the main reason for this. Thus, if we find connection between an explanatory and our dependent variable (MSF as a ratio to card payments), we might find an effective tool to further extend the card acquiring network. This obviously does not mean, that it will solve all problems, since a small proportion of merchants reject the provision of electronic payment methods presumably due to transparency reasons (i.e. tax evasion). However, since in Hungary basically all merchants, restaurants, hotels are monitored by the Tax Authority real-time through online cash register machines, the proportion of grey economy decreased significantly, thus we can reasonably expect, that the lowering of MSFs can be a help indeed to a large number of retailers. We estimated the following equation:

ratio of merchant service fees to card payment turnover $\left(\mathrm{d} \mathrm{l}_{-} \mathrm{msfrat}\right)=\beta_{0}+\beta_{1} \mathrm{~d} \mathrm{l}_{-}$consum $+\beta_{2} \mathrm{~d} \mathrm{l}_{-}$ 
$\operatorname{posnfc}+\beta_{3} \mathrm{dl} \_$cardnfc $+\beta_{4} \mathrm{dl} \_$posrat $+\beta_{5} \mathrm{dl} \_\mathrm{mif}+\beta_{6} \mathrm{dl}{ }_{-}$ incrat $+\beta_{7} \mathrm{dl} \_$mifrat $+\beta_{8} \mathrm{dl} \_$cardtr $+\mu$.

According to results in Table 2, the level of interchange fees showed a significant positive relationship with our dependent variable. In other words this means, that the decrease of interchange fees will result in a decline in the level of MSFs as well, which can be especially important to smaller retailers, who are more cost-sensitive, and where MSF levels are higher. It is also to mention, that at the majority of larger merchants, card payment was already available before IFR, therefore the further extension of the Hungarian card acquiring network can only made by the inclusion of a growing number of small shops with low turnover, mostly in villages (see results on the card acquiring in Hungary in GVH 2019 and Kajdi-Nemecskó 2020).[27, 34].

In order to further investigate the case of these small merchants, we filtered our card payment turnover and MSF data. MNB collects data on MSFs by five merchant categories, based on the quarterly card payment turnover:

- Category 1: less than HUF 1 million ( EUR 2,800)

- Category 2: HUF 1 million - HUF 2.5 million ( EUR $2,800-7,100)$

- Category 3: HUF 2.5 million - HUF 25 million ( EUR $7,100-71,000)$

- Category 4: HUF 25 million - HUF 250 million ( EUR $71,000-710,000)$

- Category 5. above HUF 250 million ( EUR 710,000)

From these subgroups, we chose category 1 and 2, as the smallest merchants, where actual changes were expected from IFR. Again, we used the same explanatory variables discussed above, with a dependent variable of the number of merchants in category 1, category 2, and category 1 and 2 together. First, we estimated the following equation to merchants in category 1 :

number of card acquiring merchants (d1_merchnum cat 1$)=\beta_{0}+\beta_{1} \mathrm{dl}{ }_{-}$consum $+\beta_{2} \mathrm{dl} \_$posnfc $+\beta_{3} \mathrm{dl} \_$card$\mathrm{nfc}+\beta_{4} \mathrm{dl} \_$posrat $+\beta_{5} \mathrm{dl} \_\mathrm{mif}+\beta_{6} \mathrm{dl} \_$incrat_cat $1+\beta_{7} \mathrm{dl}$ mifrat_cat $1+\beta_{8} \mathrm{dl} \_$cardtr $+\mu$.

Table 2 Results of ARIMAX model on the ratio of MSF to card payment turnover in Hungary. Source Authors' calculations based on MNB data

\begin{tabular}{ll}
\hline Variable & Coefficients \\
\hline $\begin{array}{l}\text { Interchange fees } \\
\text { (dl_mif) }\end{array}$ & $\mathbf{0 . 0 5 6}^{*}$ \\
AR(6) & $(2.020)$ \\
& $-\mathbf{0 . 9 4 4} *$ \\
Constant & $(-3.323)$ \\
& $-\mathbf{0 . 0 0 5 *}$ \\
& $(-1.882)$ \\
\hline
\end{tabular}

Numbers in parenthesis are t-statistics.

*Indicates significance at 5 percent level
Table 3 Results of ARIMAX model on the number of card-acquiring merchants in category 1. Source: Authors' calculations based on MNB data

\begin{tabular}{ll}
\hline Variable & Coefficients \\
\hline Ratio of POS-terminals installed within the State's & $\mathbf{0 . 2 5 1 * *}$ \\
programme (dl_posrat) & $(4.763)$ \\
Ratio of interchange fees to card payment turnover in & $\mathbf{- 0 . 1 4 1 * *}$ \\
category 1 (dl_mifrat) & $(-2.246)$ \\
AR(1) & $\mathbf{0 . 3 7 2 *}$ \\
AR(2) & $(1.928)$ \\
& $-\mathbf{0 . 4 4 6}^{* *}$ \\
\hline
\end{tabular}

*and **Indicates significance at 10 and 5 percent level respectively. Mifrat was calculated by merchant categories i.e. interchange fees paid by merchants in the given category, compared to the card payment turnover of retailers in the given category

Numbers in parenthesis are t-statistics.

Our model on the smallest merchants showed (Table 3.) on one hand positive effects of the national POS-terminal implementation programme, which corresponds to market information of MNB, i.e. mainly retailers with the lowest turnover were targeted by PSPs participating in the programme. Besides, it is also important that negative relationship was identified with interchange fee burdens of merchants, thus the reduction of interchange fees results in the higher number of card acquiring merchants in this category.

We also examined the second smallest retailer category, using the following equation, similar to category 1 :

number of card acquiring merchants (dl_merchnum cat 2$)=\beta_{0}+\beta_{1} \mathrm{dl} \_$consum $+\beta_{2} \mathrm{dl} \_$posnfc $+\beta_{3} \mathrm{dl} \_$card$\mathrm{nfc}+\beta_{4} \mathrm{dl} \_$posrat $+\beta_{5} \mathrm{dl} \_\mathrm{mif}+\beta_{6} \mathrm{dl} \_$incrat_cat $2+\beta_{7} \mathrm{dl}$ mifrat_cat $2+\beta_{8} \mathrm{dl} \_$cardtr $+\mu$.

In the second category we can also see (Table 4) a negative relationship between the number of merchants and interchange fee burdens compared to card payment turnover, which means that approximately 0.2 percent decrease in IF implies cca. 1 percent increase in the number of merchants of second category. This also supports our previously articulated hypothesis, that the IFR is especially important for retailers with low turnover.

Concerning the larger merchants, we Table found different relationships between the variables. For the largest retailer category, we could not fit a model, where the relationship with any of the explanatory variables proved to be significant. (Table 5) None of the policy measures were effective in the case of the largest merchants, but this is obviously due to their already low MSF (because of the high bargaining power of these large merchants). However, for the middle categories significant influencing factors could be identified. For these merchants neither the IFR, nor the POS programme proved to be significant, but rather the total 
Table 4 Results of ARIMAX model on the number of cardacquiring merchants in category 2. Source Authors' calculations based on MNB data

\begin{tabular}{lc}
\hline Variable & Coefficients \\
\hline Ratio of interchange fees to card payment turnover in category 2 (dl_mifrat) & $\mathbf{- \mathbf { 0 . 2 2 6 } ^ { * }}$ \\
& $(-3.067)$ \\
\hline
\end{tabular}

*Indicates significance at 5 percent level

Numbers in parenthesis are t-statistics.
Table 5 Results of ARIMAX model on the number of card-acquiring merchants in category 3 and 4. Source Authors' calculations based on MNB data

\begin{tabular}{lll}
\hline Variable & $\begin{array}{l}\text { Category3 } \\
\text { Coefficients }\end{array}$ & $\begin{array}{l}\text { Category4 } \\
\text { Coefficients }\end{array}$ \\
\hline Card payment turnover & $\mathbf{1 . 2 6 2 *}$ & $\mathbf{1 . 7 7 3 *}$ \\
(dl_cardtr) & $(11.800)$ & $(12.207)$ \\
Ratio of contactless cards & $\mathbf{0 . 1 6 6 *}$ & \\
(dl_cardnfc) & $(2.331)$ & \\
AR(3) & $\mathbf{- 0 . 3 8 1 ^ { * }}$ & \\
& $(-1.895)$ & $-\mathbf{0 . 0 1 3}^{*}$ \\
Constant & $\mathbf{- 0 . 0 1 3 *}$ & $(-2.369)$ \\
\hline
\end{tabular}

*Indicates significance at 5 percent level

Numbers in parenthesis are t-statistics.

number of card transactions in Hungary, which basically corresponds to the changing consumer payment habits. It is also interesting, that positive relationship occurred with the ratio of contactless cards, i.e. the higher the prevalence of contactless technology, the larger number of merchants will accept cards. In other words, the ratio of card acquirers was already high, and acquiring costs were already low enough in these merchant categories, thus neither the IFR, nor the POS programme was an effective tool to incentivize cash-only merchants to start card acceptance. The progress in these categories was rather market driven, i.e. the growing demand from the consumer side to use cards forced the remaining non-card-acquirer merchants to implement POS terminals.

\section{IFR effects on the issuer side}

We also investigated the possible IFR effect on the card issuer side, namely on card fees paid by the cardholders and the total number of cards in Hungary. As we described above, it is a frequently articulated argument against IFR, that lower interchange levels result in higher cardholder fees due to the pass-through effect on the PSPs' side, which will eventually reduce the number of cards. Therefore, we examined the issuer side as well. (Table 6) Two models were built to measure the effects of IFR:
Table 6 Results of sARIMAX model on the cardholders' fees and the total number of cards issued in Hungary. Source Authors' calculations based on MNB data

\begin{tabular}{lllll}
\hline Model 1 & & & Model 2 & \\
\cline { 1 - 2 } \cline { 5 - 5 } Variable & Coefficients & & Variable & Coefficients \\
\hline dl_cardnfc & $\mathbf{0 . 3 4 8} *$ & & dl_consum & $\mathbf{0 . 0 3 0 *}$ \\
& $(3.685)$ & & & $(3.106)$ \\
dl_mifrat & $\mathbf{0 . 0 2 7}$ & & dl_mifrat & $\mathbf{0 . 0 1 6}$ \\
& $(0.225)$ & & & $(1.270)$ \\
dl_mif & $\mathbf{0 . 0 3 0}$ & & dl_mif & $\begin{array}{c}\mathbf{0 . 0 0 6} \\
\end{array}$ \\
& $(0.500)$ & & $(-0.991)$ \\
\hline
\end{tabular}

*Indicates significance at 5 percent level

Numbers in parenthesis are t-statistics.

- in the first model card fee was explained with the rate of NFC ready cards within all the cards (to control for possible increases in card production costs due to technological developments), the two variables that represent interchange fee effect and a first-order autoregressive variable;

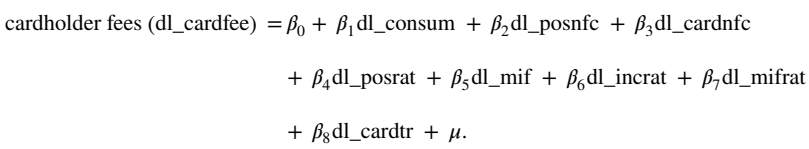

- In the second model total number of cards was regressed with the same two interchange fee variables, along with the turnover and AR(1) variables.

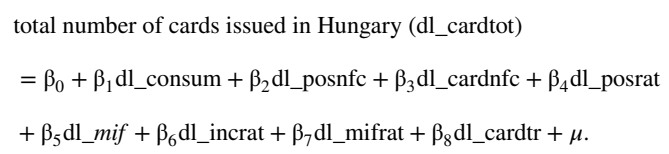

As we expected, the two variables that we tried to capture the interchange fee effects were not statistically significant, therefore we could not identify any effect of the interchange fee reduction on the card issuer side. Since the models have two very insignificant variables, we did not attempt to interpret the slope parameters.

Based on the estimated models we could not find evidence that the IFR had a significant (adverse) effect on the issuer side. This can presumably be attributed to the high level of market competition, i.e. although the demand side is solid, since it is essential nowadays to possess a card, but 
due to the heavy competition issuer PSPs decided to bear the decrease in their revenues, instead of trying to obtain compensation with higher cardholder fees.

\section{Conclusions}

The evaluation of regulatory and public policy steps is crucial to influence market processes effectively. This ensures that if previous steps did not reach the expected goals, then they can be further adjusted, or new measures should be elaborated. With our analysis we intended to contribute to the long-lasting discussion on the role of interchange fees and the success of POS-terminal implementation programmes. However, it is important that our study did not aim to provide empirical results on the optimal level of interchange fees, we just examined whether the regulatory changes during the recent years actually facilitated the further development of the payment card market.

First, it is worth to emphasize, that MNB has such a comprehensive and detailed datasets on the card acquiring service revenues of PSPs (or MSFs from the retailers point of view), which is perhaps unique even in international comparison, therefore our results are presumably more reliable than those which are based merely on sample surveys. According to our descriptive results it is clear, that the level of MSFs decreased indeed after the IFR, thus for the vast majority of merchants where acquiring costs was an issue, the regulation was advantageous, which confirms the findings of Ardizzi - Zangrandi (2018), [24] EC (2020) and Górka (2018) [23]. This also means that the pass-through rate towards merchants was high in the case of Hungary, i.e. those PSPs which provide acquiring services did not hold back the extra revenues coming from the decrease in interchange fees. It is also important, that IFR facilitated the reduction of market concentration and the market-entry of new PSPs. Besides the IFR, the other major regulatory and policy step was the POS-implementation programme, which actually helped to increase the number of terminals in Hungary.

Second our time series analysis showed that the number of card-acquiring merchants was mainly affected by the POS-terminal implementation programme and household consumption in general. It was also interesting that the spread of NFC technology on the issuer and acquirer side was only significant in our models for mid-size merchants. This is presumably due to the fact, that the contactless technology mainly effects the convenience of the payment process, therefore it rather boosts the more frequent usage of cards, but merchants will not introduce acquiring only because of the smooth user experience.

Third, our models proved that for the smaller merchants, where the ratio of card acquiring is the lowest, the IFR was an effective tool indeed. The diverse effects on different merchant categories is also in line with the findings of Shy (2012) and Layne-Farrar (2013) [15, 17]. By decreasing the burdens of those merchants which are the most cost-sensitive, regulators can actually contribute to the extension of the card acquiring network. It should also be noted that our data were not panel data, thus merchants could change categories throughout the examined periods. This does not alter the major tendencies, but can be an underlying cause for the differing significance of our interchange fee explanatory variables (mif and mifrat), referring basically to the same phenomenon, i.e. the cost of retailers.

Fourth, our models also showed that no significant disadvantageous effects appeared concerning the number of issued cards or the average level of card fees. In the literature there are diverse conclusions concerning the effects of IFR on the issuer side, however our latter finding on card fees is in accordance with results of the analyses on the US (Hayashi 2013) [19] and European (EC 2020) [26] markets. In other words, the reduced revenues on the issuer side did not cause major negative changes in Hungary, and card issuing PSPs did not compensate by increasing consumer fees in general.

Finally, it is to be noted, that during the upcoming years the Hungarian card payments market might face remarkable changes, which may underpin the necessity of further analyses. The emergence of COVID 19 virus might have changed users' payment habits in the long run as well, pushing them towards the more frequent use of contactless payments. This was facilitated by the lifting of value thresholds for transactions without the necessity of entering PINs: in April 2020 this limit was raised from HUF 5,000 (appr. EUR 14) to HUF 15,000 (appr. EUR 43), which can contribute to the smooth user experience during card purchases. Another major change is that according to the new measure introduced in the Act CLXIV of 2005. On commerce, those companies which are obliged to use online cash registers (i.e. the Tax Authority can monitor them in a real-time manner, covering basically the whole retail, and large segments of the tourism sector) must provide electronic payment options for customers from 1 January 2021. On one hand this is a huge business opportunity for acquiring PSPs to expand their business. However, instant payment service was launched on 2 March 2020, which might pose a serious challenge for traditional card acceptance. All in all, these factors also yield the possibility of profound future research activity in this field in Hungary. 


\section{Declarations}

Conflict of interest The authors declare that they have no conflict of interest.

\section{References}

1. Esselink H, Hernández L. 2017. The use of cash by households in the euro area. ECB Occasional Paper (201).

2. The aggregate costs of payments in Denmark were kr. 15.6 billion in 2016. Danish Payment Council, 2018.

3. Schmiedel H, Kostova GL, Ruttenberg W. 2012. The social and private costs of retail payment instruments: a European perspective. Frankfurt am Main, Germany: European Central Bank, Contract No.: 137.

4. Rochet, J.-C., and J. Tirole. 2011. Must-take cards: Merchant discounts and avoided costs. Journal of the European Economic Association. 9 (3): 462-495.

5. Vickers, J. 2005. Public policy and the invisible price: Competition law, regulation and the interchange fee. Competititon LJ. 4: 5 .

6. Rolfe A. 2016. Available from: https://www.paymentscardsan dmobile.com/contactless-cards-comparative-view-two-markets/.

7. Group ECW. (2015). Final report on mobile and card based contactless proximity payments. Frankfurt am Main: European Central Bank, Contract No.: ERPB CTLP 70-15.

8. Schmiedel H, Börestam A. 2011. Interchange fees in card payments. Frankfurt am Main, Germany: European Central Bank, Contract No.: 131.

9. The Economic Impact of Interchange Fee Regulation in the UK. Chancery Lane London WC2A IQU: Europe Economics, 2013.

10. Reisinger, M., and H. Zenger. 2019. Interchange fee regulation and service investments. International Journal of Industrial Organization. 66: 40-77.

11. Keszy-Harmath É, Kóczán G, Kováts S, Martinovic B, Takács K. 2012. The role of the interchange fee in card payment systems. Budapest, Hungary: MNB, Contract No.: 96.

12. Survey on merchants' costs of processing cash and card payments. Luxembourg: European Commission Directorate-General for Competition, 2015a.

13. Górka J. editor.2014. Merchant indifference test application-A case for revising interchange fee level in Poland. The usage, costs and benefits of cash-Conference Volume. (pp75-157).

14. W Bolt N Jonker M Plooij 2013 Tourist test or tourist trap? De Nederlandsche Bank Unintended consequences of debit card interchange fee regulation. SSRN Electronic Journal. https://doi.org/ $10.2139 /$ ssrn. 2369799

15. Layne-Farrar, A. 2013. Assessing the Durbin Amendment's Debit Card Interchange Fee Cap: An Application of the "Tourist Test" to US Retailer Data. Review of Network Economics. 12 (2): 157-182.

16. Wang, Z. 2012. Debit card interchange fee regulation: some assessments and considerations. FRB Economic Quarterly. 98 (3): $159-183$.

17. Shy, O. 2012. Who gains and who loses from the 2011 debit card interchange fee reform? Federal Reserve Bank of Boston. https:// doi.org/10.2139/ssrn.2376628.

18. Hayashi F. 2012. The new debit card regulations: Initial effects on networks and banks. Economic Review-Federal Reserve Bank of Kansas City 79.

19. Hayashi F. 2013. The new debit card regulations: Effects on merchants, consumers, and payments system efficiency. Economic Review-Federal Reserve Bank of Kansas City 89.

20. Zywicki, T.J., G.A. Manne, and J. Morris. 2014. Price controls on payment card interchange fees: The US experience. George Mason
Law \& Economics Research Paper. https://doi.org/10.2139/ssrn. 2446080.

21. Evans, D.S., H.H. Chang, and S. Joyce. 2013. The Impact of the US debit card interchange fee caps on consumer welfare: An event study analysis. University of Chicago Coase-Sandor Institute for Law \& Economics Research Paper. https://doi.org/10.2139/ssrn. 2342593.

22. Iranzo J, Fernández P, Matías G, Delgado M. 2012. The effects of the mandatory decrease of interchange fees in Spain Available from: https://repositorio.uam.es/bitstream/handle/10486/10839/ 54105_informe_matiasclavero.pdf?sequence $=1$.

23. Górka, J. 2018. Interchange Fee Economics: To Regulate or Not to Regulate. Warsaw, Polland: Palgrave Macmillan.

24. Ardizzi G, Savini Zangrandi M. 2018. The impact of the interchange fee regulation on merchants: evidence from italy. Bank of Italy, Contract No.: 434.

25. Veljan, A. 2018. A critical review of the European commission's multilateral interchange fee regulation. Journal of Payments Strategy \& Systems. 12 (3): 232-244.

26. Pavel F, Kornowski A, Knuth L, Rücker C, Bernstein M, Dukart L-M, et al. 2020. Study on the application of the Interchange Fee Regulation. European Commission Directorate General for Competition.

27. Jelentés a bankkártya-elfogadás piacán lefolytatott ágazadi vizsgálatról. Budapest, Hungary: Gazdasági Versenyhivatal, 2019.

28. Veljan, A. 2020. The influence of intra- and inter-system concentration on the pre-regulated setting of interchange fees within cooperative card payment networks. Journal of Banking Regulation. 21 (2): 139-151.

29. Illyés, T., and L. Varga. 2015. Show me how you pay and I will tell you who you are-Socio-demographic determinants of payment habits. Financial Economic Review. 14 (2): 25-61.

30. Magyar Nemzeti Bank (MNB). 2020. Payment systems report. Budapest, Hungary: Magyar Nemzeti Bank.

31. Payment data Budapest, Hungary: Magyar Nemzeti Bank; 2020a. Available from: https://www.mnb.hu/en/statistics/statistical-dataand-information/statistical-time-series/xiv-payment-systems/ payment-data

32. The Interchange Fees Regulation. European Commission, 2015b.

33. Magyar Nemzeti Bank (MNB). 2019. Payment systems report 2018. Budapest: Magyar Nemzeti Bank.

34. Kajdi, L., and I. Nemecskó. 2020. Regional features of card payments in Hungary. Financial and Economic Review. 19 (1): $65-89$.

Publisher's Note Springer Nature remains neutral with regard to jurisdictional claims in published maps and institutional affiliations.

László Kajdi is senior economic analyst at the Central Bank of Hungary at Directorate Financial Market Infrastructures. He received his MA in economics at University of West Hungary, at present he is completing his $\mathrm{PhD}$ at University of Pécs. He is the author of several articles and other publications in retail payments including instant and card payments.

Milán Kiss is senior economic analyst at the Central Bank of Hungary responsible for leading the market infrastructures regulations team. He graduated in University of Miskolc majoring finance and accounting, furthermore, completed law school at Pázmány Péter Catholic University. He is currently responsible for participating the development of payments related regulatory framework as well as providing legal interpretations and analysis of market infrastructures. Also, he is a lecturer at Budapest Institute of Banking. 